\title{
Histopatología testicular de ratas BIOU: Wistar expuestas a malatión
}

\section{Testicular histopathology of rats BIOU: Wistar exposed to malathion}

\author{
Serrano $R^{1}$, Hernández $G A^{1}$, Hung $S^{1}$, Lozano $R^{2}$, Paoli $M^{3}$, Gómez $R^{4}$.
}

${ }^{1}$ Médico especialista en Medicina Interna y Endocrinología.

Universidad de Los Andes. Mérida, Venezuela.

${ }^{2}$ Médico especialista en Patología. Universidad de Los Andes. Mérida, Venezuela.

${ }^{3}$ Médico especialista en Endocrinología. Doctora en Ciencias Médicas. Profesora titular del posgrado de Endocrinología de la Universidad de Los Andes. Mérida-Venezuela.

${ }^{4}$ Médico especialista en Medicina Interna y Endocrinología. Doctor en Ciencias Médicas. Fellow en Andrología. Director del posgrado de Endocrinología de la Universidad de Los Andes. Mérida, Venezuela.

Autor de correspondencia: Ronald Andrés Serrano Uribe Correo electrónico: rounnald@gmail.com

Fecha de recepción: 13/02/2019

Fecha de aceptación: 20/03/2019

\section{Resumen}

Objetivo: determinar la histopatología de los testículos de ratas BIOU: Wistar expuestas crónicamente a malatión en comparación con ratas no expuestas.

Métodos: estudio experimental con 20 ratas machos asignadas al azar, 10 al grupo control y 10 al expuesto. La exposición consistió en la aplicación crónica de malatión de manera inhalada una vez a la semana durante 2 horas, por 14 semanas; las dosis empleadas fueron equivalentes a las usadas por humanos en agricultura. El grupo control fue expuesto a un placebo (agua destilada) al aire libre por el mismo lapso. Luego, fueron sacrificadas, se obtuvo una muestra sérica para la determinación de la acetilcolinesterasa y se les extrajeron los testículos para el estudio histopatológico.

Resultados: los niveles de acetilcolinesterasa fueron significativamente más bajos $(p=0,0001)$ en el grupo expuesto que en el grupo control. En el estudio histopatológico con microscopia de luz, en el grupo expuesto se evidenció una vacuolización del epitelio germinal en el $50 \%$ de los casos ( $p$ $=0,016)$ para un odds ratio (OR) de 3,00 (95\%: 1,46-6,13), así como espermatogénesis incompleta en el $40 \%(p=0,043)$ para un OR de 2,66 (95 \%: 1,41-5,02); por su parte, no hubo alteraciones en el grupo control. Se observó una correlación inversa significativa ( $p=0,0001)$ entre el número de alteraciones histopatológicas y la actividad de la acetilcolinesterasa.

Conclusiones: estos resultados demuestran que la exposición crónica a malatión en ratas BIOU: Wistar puede producir efectos deletéreos en el sistema reproductivo de las ratas.

Palabras claves: disruptores endocrinos, histopatología, testículo, malatión.

\section{Abstract \\ Objective: To determine the histopathology of the testes of BIOU: Wistar rats chronically exposed to malathion compared to non-exposed rats.}

Methods: Experimental study with 20 male rats randomized, 10 to the control group and 10 to the exposed group. The exposure consisted in the chronic application of inhaled malathion once a week for 2 hours for 14 weeks, with equivalent doses to those used by humans in agriculture. The control group was exposed to a placebo (distilled water) in the open air for the same interval time. Afterwards, they were sacrificed, a serum sample was obtained for the determination of acetylcholinesterase and the testicles were extracted for histopathological study.

Results: Acetylcholinesterase levels were significantly lower ( $p=0.0001$ ) in the exposed group than in the control group. In the histopathological study with light microscopy, in the exposed group, vacuolation of the germinal epithelium was observed in $50 \%$ of the cases ( $p=0.016$ ) for an odds ratio of 3.00 (95\%:1.466.13), as well as incomplete spermatogenesis in $40 \%(p=0.043)$ for an odds ratio of 2.66 (95 \%:1.41-5.02), while there were no alterations in the control group. There was a significant inverse correlation ( $p=0,0001)$ between the number of histopathological alterations and acetylcholinesterase activity.

Conclusions: These results show that chronic exposure to malathion in BIOU: Wistar rats can produce deleterious effects on their reproductive system.

Keywords: endocrine disruptors, histopathology, testis, malathion. 


\section{Introducción}

Un disruptor endocrino es aquella sustancia química exógena o mezcla de compuestos que se encuentra en el medio ambiente y tiene la capacidad de interferir con la síntesis, secreción, transporte, acción, metabolismo o eliminación de las hormonas naturales presentes en el cuerpo que son indispensables para la homeostasis, la reproducción y los procesos de desarrollo ${ }^{(1,}$ 2). Las investigaciones llevadas a cabo han demostrado los efectos potencialmente dañinos de los disruptores endocrinos en el cuerpo humano y han permitido aumentar los conocimientos en el área de la biología y la toxicología ambiental.

Es conocido que los compuestos con mecanismos de disrupción endocrina pueden afectar seriamente la reproducción humana, al evidenciarse una disminución considerable en los biomarcadores de fertilidad, en particular en el recuento de espermatozoides en poblaciones humanas que han estado expuestas a estas sustancias ${ }^{(3-6)}$. Debido a los efectos tóxicos que estas sustancias pueden generar, se han implementado medidas de restricción para su uso en ciertos países, en donde la exposición de la población es importante. Sin embargo, la exposición humana a los disruptores endocrinos es inevitable cuando estos productos químicos son utilizados en las industrias o están ampliamente dispersos en el medioambiente, como es el caso de los pesticidas.

Un pesticida se define como una sustancia o combinación de productos químicos usados para prevenir, destruir, repeler y mitigar plagas, como nemátodos, ratas, ácaros, insectos, maleza y hongos ${ }^{(7)}$. Dentro de los pesticidas considerados como disruptores endocrinos se encuentran los organoclorados y los organofosforados. El malatión, un pesticida organofosforado, ha sido ampliamente utilizado en la agricultura y en el uso doméstico para el control de plagas, por lo que ha generado una gran exposición a altos niveles tanto en humanos como en animales ${ }^{(8)}$.

El malatión tiene la propiedad de inhibir la actividad de la acetilcolinesterasa en tejidos específicos, así como de afectar el sistema reproductivo masculino y la espermatogénesis. Estudios experimentales con ratones demostraron que la exposición a este pesticida reduce la producción de espermatozoides, disminuye las formas espermáticas normales, altera la esteroidogénesis e induce la apoptosis de las células germinales con la depleción subsiguiente del epitelio seminífero ${ }^{(9-12)}$. El objetivo de este estudio fue comparar los cambios histológicos de los testículos y la actividad de la acetilcolinesterasa sérica en ratas expuestas crónicamente a malatión inhalado con respecto a ratas no expuestas.

\section{Materiales y métodos}

Se realizó un estudio de investigación básica de tipo experimental en animales. Se utilizaron ratas machos de la línea BIOU: Wistar, con un peso promedio de $300 \mathrm{~g}$, las cuales fueron suministradas por el bioterio de la Universidad de los Andes (Mérida,
Venezuela) y trasladadas a las instalaciones del laboratorio de farmacología y toxicología de la facultad de medicina de la misma universidad; allí permanecieron durante todo el trabajo. Se ubicaron en sus respectivas jaulas, se pesaron y se les dio una semana como período de adaptación. Las ratas se sometieron a ciclos constantes de 12 horas de luz y de oscuridad, y se mantuvieron a una temperatura de $22-24^{\circ} \mathrm{C}$, con ventilación continua. Todas las ratas se manipularon de acuerdo con la guía estándar para el cuidado y uso de animales de laboratorio.

Se utilizó como material tóxico el malatión, nombre comercial Malathion ${ }^{\circledR} 57 \%$, cuyos componentes son el malatión al $57 \%$ e ingredientes aditivos (43\%). Este es fabricado por Insecticidas Internacionales C.A. (INICA). La preparación se realizó de acuerdo con las recomendaciones del fabricante; esto es, una dilución en una proporción de 1:100 con agua destilada. Se estudiaron 20 ratas, las cuales se distribuyeron al azar en dos grupos, 10 al grupo control y 10 al expuesto. El grupo expuesto fue sometido a la aplicación de malatión de manera inhalada. El tiempo y la frecuencia por semana de exposición al malatión en los animales de experimentación, así como la cantidad y preparación de este, se hicieron de acuerdo con las instrucciones del fabricante, en dosis equivalentes a las usadas por los humanos en agricultura.

La cantidad fue calculada de acuerdo con el área de aplicación, teniendo en cuenta que se usa de 1 a 3 litros de malatión por hectárea. Se aplicaron, de acuerdo con las medidas del área, $4 \mathrm{~mL}$ de la dilución (1:100) a través de una asperjadora sobre las jaulas, en una instalación al aire libre, donde quedaron expuestas las ratas por dos horas. Luego fueron llevadas dentro de las instalaciones del laboratorio y fueron observadas diariamente, vigilando signos de toxicidad aguda y, por ende, sufrimiento del animal.

La exposición se hizo una vez a la semana por catorce semanas (crónica). Las ratas del grupo control fueron expuestas a un placebo (agua destilada), de igual manera, al aire libre por el mismo intervalo de tiempo. Al término de la exposición, antes de la anestesia con enflurano inhalado al $1 \%$ durante aproximadamente 10 minutos, las ratas de cada grupo fueron sacrificadas. Se practicó la necropsia. Las muestras de sangre se obtuvieron por punción ventricular para la determinación de la acetilcolinesterasa, y el suero poscentrifugación fue conservado a $-20^{\circ} \mathrm{C}$ hasta el momento de su análisis. Después, se extrajeron ambos testículos, los cuales se fijaron con líquido de Bouin durante 24 horas; luego, se seccionó en segmentos pequeños, máximo de $0,5 \mathrm{~cm}$.

Luego de la fijación, se siguieron los pasos de lavado, aclaramiento, fijación e inclusión en parafina y después se realizaron los respectivos cortes con el microtomo. Los cortes de $5 \mu \mathrm{m}$ se colocaron en un portaobjetos y fueron coloreados con hematoxilina-eosina, para ser analizados por microscopía de luz. La determinación de la acetilcolinesterasa se llevó a cabo en el laboratorio de farmacología de la facultad de medicina. Las muestras de 
suero sanguíneo fueron procesadas por el método de hidroxamato de Hestrin, modificado por Truhaut y Vernin ${ }^{(13)}$, y analizadas por espectrofotometría a $520 \mathrm{~nm}$. La manipulación de los animales se llevó a cabo cumpliendo con el reglamento establecido por la comisión de bioética en BIOULA para protocolos de investigación y docencia que involucran animales de laboratorio, la cual fue aprobada para la realización del estudio.

Para el análisis de los datos se usó el programa estadístico SPSS para Windows, versión 20. Las variables cuantitativas se expresaron como promedio \pm desviación estándar y mediana (rango intercuartil); y para la comparación se usó la prueba de la U de Mann Whitney. Se realizó una correlación de Spearman entre las variables estudiadas. Las variables cualitativas se presentaron como número absoluto y porcentaje, se estableció su asociación mediante la aplicación de la prueba exacta de Fisher y se determinó la probabilidad de riesgo (odds ratio [OR]) de alteración testicular por exposición al malatión. Se consideró un nivel de significancia cuando el valor de $p$ fue menor de 0,05 .

\section{Resultados}

Se analizaron 20 ratas Wistar, 10 expuestas y 10 controles. En la Tabla 1 se presentan los valores de peso y acetilcolinesterasa en el grupo control y el grupo expuesto a malatión. Con respecto al crecimiento corporal, no se observaron diferencias significativas en el peso inicial y final del estudio entre los animales del grupo control y el expuesto. Los niveles de acetilcolinesterasa fueron significativamente más bajos en el grupo expuesto $(p=0,0001)$ en comparación con el grupo control.

En cuanto a la relación entre los niveles de acetilcolinesterasa y el número de anormalidades histológicas presentes en los testículos de las ratas (Figura 1), se encontró una relación inversa significativa fuerte $(r=-0,862 ; p=0,000)$; esto es, en la medida que disminuyen los niveles de acetilcolinesterasa, se incrementa el número de anormalidades histológicas presentes.
Figura 1. Correlación de los niveles de acetilcolinesterasa (UC/50 $\mu \mathrm{L}$ ) con el número de anormalidades histológicas presentes en el grupo expuesto.

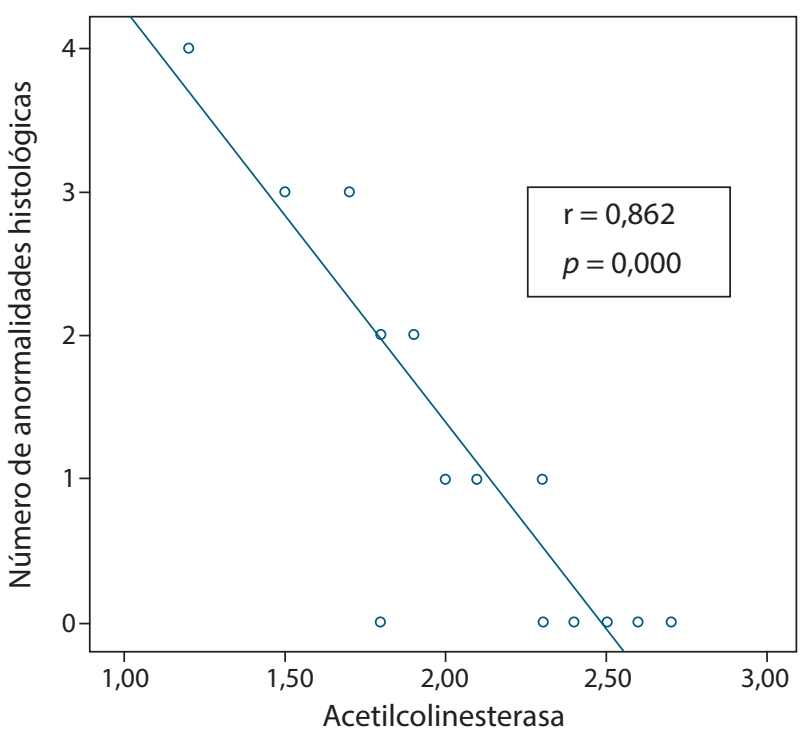

\section{Hallazgos histopatológicos a la microscopía de luz}

En el estudio histológico con microscopía de luz en los testículos de los animales expuestos al malatión se observó una vacuolización del epitelio germinal en el 50 \% de los casos. La espermatogénesis avanzaba hasta la etapa de espermatocito I en el $40 \%$ de los epitelios. Las células germinales mostraron núcleos picnóticos. El intersticio presentó hiperemia moderada; y los túbulos seminíferos, disminución de su diámetro en el 30 \%. Se encontró hipertrofia de las células de Leydig, hialinización de la membrana basal, fibrosis peritubular, desprendimiento del epitelio germinal y engrosamiento de la membrana basal en el $10 \%$ de los casos, mientras que en las muestras del grupo control no se observaron alteraciones histopatológicas.

Tabla 1. Valores de peso corporal y actividad de acetilcolinesterasa en el grupo control y el grupo expuesto a malatión

\begin{tabular}{c|c|c}
\hline Variables & Grupo control $(\mathbf{n = 1 0})$ & Grupo expuesto (n=10) \\
\hline Peso inicial (g) & $234,1 \pm 33,9$ & $224,5 \pm 31,1$ \\
& $241,5(200,0-262,5)$ & $212,5(200,2-246,7)$ \\
\hline Peso final (g) & $321,2 \pm 54,4$ & $323,4 \pm 27,8$ \\
& $305,0(287,2-357,5)$ & $321,5(305,0-342,5)$ \\
\hline Acetilcolinesterasa $(\mathrm{U} / \mathrm{mL})$ & $2,41 \pm 0,24$ & $1,76 \pm 0,36^{*}$ \\
& $2,40(2,37-2,60)$ & $1,85(1,42-2,02)^{*}$ \\
\hline
\end{tabular}

Datos en $\mathrm{X} \pm \mathrm{DE}$ y mediana (rango intercuartil). Prueba de Mann-Whitney: ${ }^{*} p=0,0001$. 
La asociación de la exposición al malatión con la vacuolización del epitelio germinal mostró significancia estadística (prueba exacta de Fisher: $p=0,016$ ) y un OR 3,00 veces mayor de presentar vacuolización del epitelio germinal en aquellas ratas expuestas a malatión, en comparación con las ratas control (IC 95 \%: 1,46-6,13) (Figura 2). Del mismo modo, la espermatogénesis incompleta presentó significancia estadística (prueba exacta de Fisher: $p=0,043$ ) y un OR 2,66 veces mayor de presentar esta alteración en las ratas expuestas al compararlas con las ratas control (IC $95 \%$ : 1,41-5,02) (Figura 3). No se pudo determinar la significancia estadística con las demás características histopatológicas presentes en los testículos de las ratas expuestas al malatión.

En la Figura 4 se muestran algunos cortes del estudio histológico (tinción con hematoxilina-eosina) de testículos del grupo control. En la Figura 4A se observa la integridad de los túbulos seminíferos con cada uno de sus componentes histológicos. La Figura 4B muestra la membrana basal tubular intacta, el intersticio sin alteraciones morfológicas con células de Leydig normales (a) y la túnica albugínea homogénea sin alteraciones (b). Los túbulos seminíferos se presentan con dife-

Figura 2. Presencia o no de vacuolización del epitelio germinal en los grupos control y expuesto al malatión. Prueba exacta de Fischer: $p=0,016$. OR: 3,00; IC $95 \%$ : 1,46-6,13.

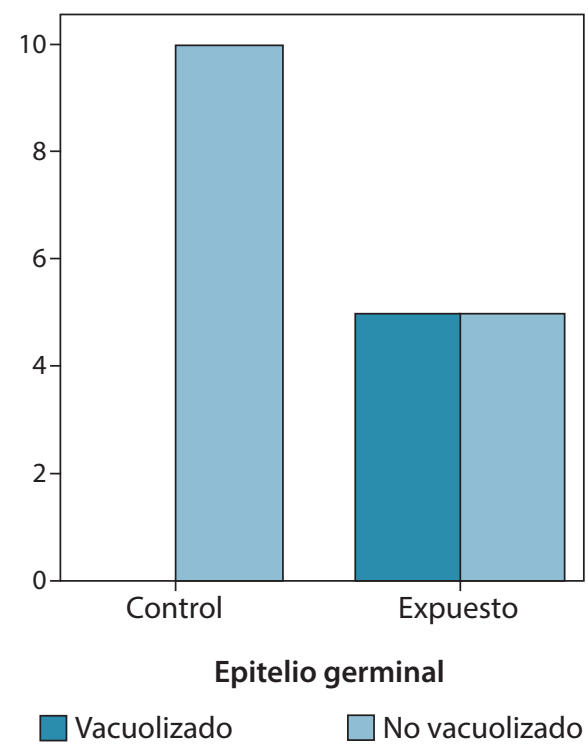

rentes estadios de maduración completa del epitelio germinal (Figura 4C). Finalmente, en la Figura 4D se muestra la cola del epidídimo en la que se observan diferentes canalículos con monocapa de células cúbicas y acúmulos de espermatozoides en la luz del tubo (a).

En la Figura 5 se muestra el estudio histológico con la tinción con hematoxilina-eosina de testículos del grupo expuesto. En la Figura 5A se observa una vacuolización moderada del epitelio germinal con maduración poco diferenciable, así como una notable cariopicnosis en la mayoría de las células germinales (a) con leve hipertrofia de las células intersticiales de Leydig (b). En la Figura 5B se puede apreciar, adyacente al capilar hiperémico (a), la membrana basal con hialinización moderada (b); y adyacente se evidencia la vacuolización intensa de los epitelios germinales con espermatogénesis incompleta (c). La Figura 5C muestra grados leves de fibrosis peritubular (a) y una disminución del diámetro del $15 \%$ de los túbulos seminíferos (b). Finalmente, la Figura 5D también muestra la disminución en los diámetros de los túbulos (a) ubicados adyacentes a la túnica albugínea (c), así como una luz tubular con espermatogénesis incompleta (b).

Figura 3. Presencia de espermatogénesis completa o incompleta en los grupos control y expuesto a malatión. Prueba exacta de Fisher: p = 0,043. OR: 2,66; IC $95 \%: 1,41-5,02$.

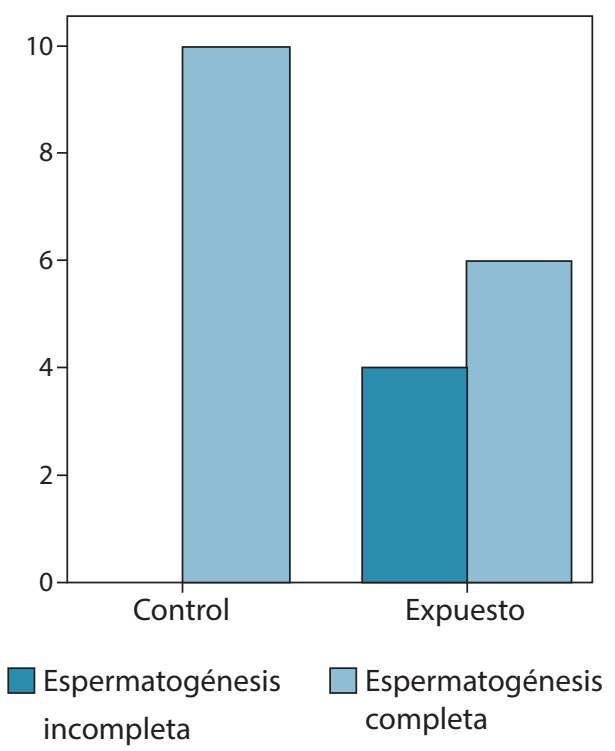


Figura 4. Fotografías de algunos cortes del estudio histopatológico (tinción con hematoxilina-eosina) de testículos de las ratas del grupo control con aumentos de 100X y 400X. Se observa la integridad de los túbulos seminíferos con diferentes estadios de maduración del epitelio germinal, membrana basal intacta e intersticio sin alteraciones morfológicas.
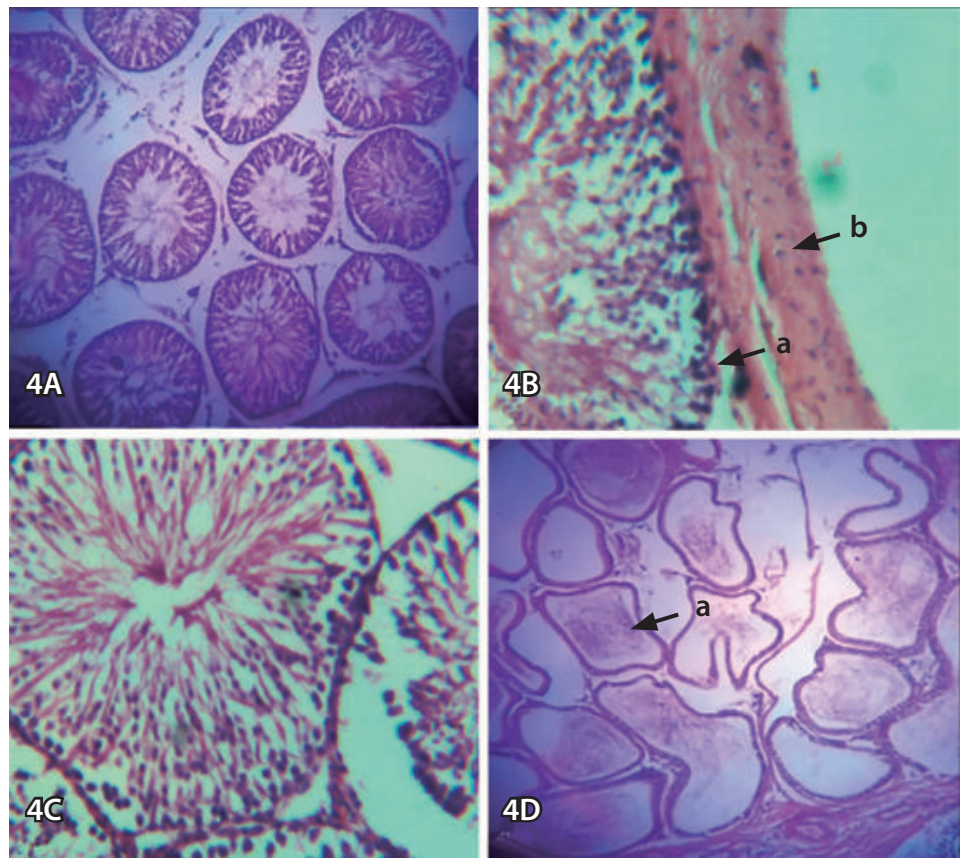

Figura 5. Cortes histológicos (tinción con hematoxilina-eosina) de testículos de las ratas del grupo expuesto con aumentos de 100X y 400X. Se observa vacuolización del epitelio germinal, espermatogénesis incompleta y disminución del diámetro de la luz de los túbulos seminíferos.
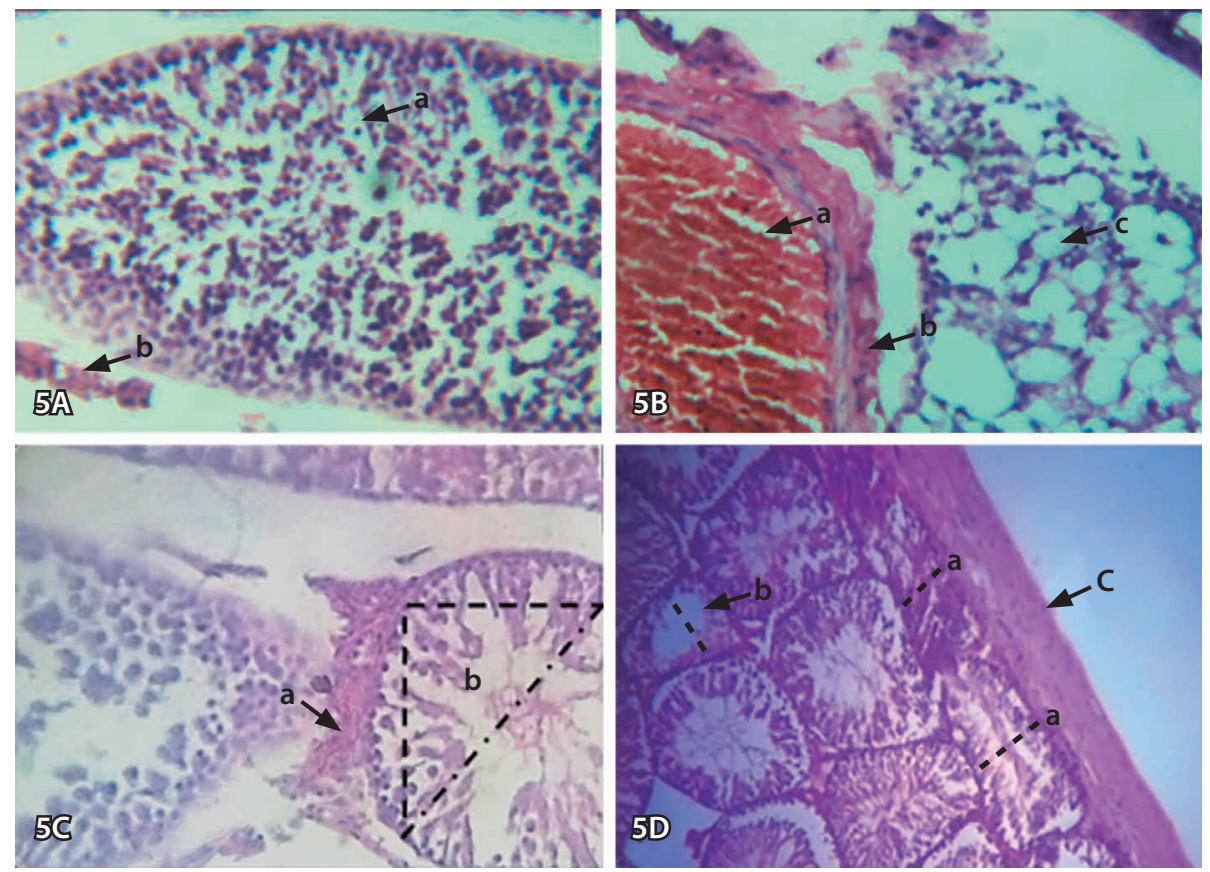


\section{Discusión}

Diversos estudios epidemiológicos han puesto en evidencia la conexión que existe entre la exposición a compuestos químicos ambientales, específicamente pesticidas, con alteraciones en los diferentes sistemas endocrinos, entre ellos el reproductivo y sus hormonas ${ }^{(14-21)}$. La exposición a pesticidas conlleva un riesgo potencial de desarrollar trastornos reproductivos masculinos, como la disminución en la calidad del semen e infertilidad; alteraciones del desarrollo fetal, que se manifiesta como anormalidades del tracto urogenital, incluyendo hipospadia y criptorquidia, y el cáncer testicular.

Los principales determinantes de los efectos tóxicos causados por los pesticidas en el sistema reproductivo humano incluyen: la dosis, la frecuencia de exposición, la vía de exposición y las características genotípicas de los sujetos expues$\operatorname{tos}^{(22,23)}$. Los posibles mecanismos fisiopatológicos que explican las alteraciones generadas por los pesticidas en la función reproductiva masculina son: el bloqueo del receptor de andrógenos y la disminución en la conversión de testosterona a dihidrotestosterona $^{(24)}$.

El malatión es un insecticida organofosforado ampliamente usado en la agricultura y la jardinería, lo que supone un riesgo de exposición en las personas que lo manipulan a través de múltiples vías como la oral, dérmica e inhalatoria. Este trabajo se basó en la intoxicación crónica con malatión por vía inhalatoria, similar a como ocurre en los humanos, para observar si se producía toxicidad en los testículos de ratas macho Wistar. En la revisión de la literatura se encontró que, en la mayoría de los estudios experimentales con ratas, las vías de administración del malatión fueron la oral ${ }^{(25-29)}$ y la intraperitoneal ${ }^{(11,30,31)}$.

En nuestro estudio experimental se considera que la intoxicación con malatión del grupo expuesto fue efectiva, ya que, como se esperaba, los niveles de acetilcolinesterasa fueron menores que en el grupo no expuesto. Esto se debe a que el malatión desarrolla su toxicidad a través de la fosforilación de la enzima acetilcolinesterasa en las terminaciones nerviosas; sin embargo, también es capaz de inhibir la acetilcolinesterasa eritrocitaria, la plasmática y la hepática, reaccionando específicamente con la zona esterásica de la enzima colinesterasa, que forma una unión estable e irreversible y la enzima queda inhabilitada para su función normal, lo que produce la disminución de su actividad ${ }^{(32)}$.

En el estudio histopatológico con microscopía de luz se demostró que cinco ratas (50 \%) presentaron vacuolización del epitelio germinal; y cuatro (40\%), espermatogénesis incompleta en el grupo expuesto a malatión; y ninguna en el grupo no expuesto. Esto resultó en una asociación significativa y un alto riesgo de alteración histopatológica de los testículos con la exposición crónica a malatión. Por otra parte, se logró determinar que, mientras más bajos fueron los niveles de acetilcolinesterasa, mayor era la presencia de alteraciones histopato- lógicas en un mismo testículo. Estas alteraciones son debidas al efecto del malatión por la vía inhalatoria, ya que fue la única situación diferente entre los dos grupos de ratas.

No se encontraron estudios de intoxicación crónica inhalatoria con malatión en animales de experimentación para comparar con nuestros resultados; sin embargo, existen dos estudios con intoxicación por vía oral, con reporte histopatológico testicular y con un seguimiento inferior al nuestro. El estudio de Geng y colaboradores ${ }^{(25)}$, en el que se expusieron ratas macho Wistar con malatión por vía oral durante aproximadamente 8,5 semanas a dosis bajas y altas, demostró un efecto dependiente de la dosis sobre la espermatogénesis dado por la pérdida y desarreglo de las células espermatogénicas y la vacuolización en el citoplasma de las células de Sertoli. Estos cambios fueron más severos en las ratas del grupo expuesto a las dosis más altas de malatión (108 mg/kg).

Por su parte, Uzun y colaboradores ${ }^{(27)}$ estudiaron el efecto tóxico que induce el malatión sobre los testículos de ratas Wistar y el efecto protector de la vitamina $\mathrm{C}$ y $\mathrm{E}$ al exponerlas por vía oral a una dosis de $27 \mathrm{mg} / \mathrm{kg}$ (1/50 de las dosis letal 50) o vitamina C (200 mg/kg) más vitamina E (200 mg/kg) diariamente durante 4 semanas. En el grupo de ratas expuestas al malatión hubo menos células espermatogénicas y necrosis en algunos túbulos seminíferos, así como edema en el tejido intersticial. Por otra parte, en el grupo de malatión más vitaminas hubo menos células espermatogénicas en algunos túbulos seminíferos y edema leve en los tejidos intersticiales. Nuestro estudio demostró resultados similares a los comentados, con el uso de dosis bajas de malatión, pero con un tiempo mucho mayor de exposición (14 semanas), que fue consistente con espermatogénesis incompleta y vacuolización del epitelio germinal.

El mecanismo fisiopatológico por el cual el malatión ejerce su acción sobre el epitelio germinal no está claro; sin embargo, se cree que los efectos del malatión y otros organofosforados relacionados se deben a su capacidad de atravesar la barrera hematotesticular y, con ello, inducir estrés oxidativo y la peroxidación lipídica. Esto produce daño y degeneración de las membranas de las células espermáticas, y a nivel intersticial tiene un impacto negativo en las células de Leydig. Lo anterior lo soportan estudios experimentales en los que la administración conjunta del malatión con antioxidantes atenúa los efectos tóxicos en el conteo, la motilidad y la morfología espermática, así como la integridad histológica del testículo ${ }^{(27,33)}$.

Otro mecanismo fisiopatológico estudiado ha sido la capacidad que puede tener el malatión en inducir la expresión de ciertos genes que producen apoptosis. Se sabe que la proteína Bax promueve la apoptosis al agotar los factores de crecimiento, mientras que la proteína Bcl-2 inhibe la apoptosis al inactivar múltiples proteínas proapoptóticas ${ }^{(34,35)}$. El balance entre la expresión de los genes que codifican estas dos proteínas determina si una célula puede o no sobrevivir ${ }^{(36,37)}$. Estudios 
experimentales en ratones muestran el efecto apoptótico del malatión al incrementar la expresión de Bax y disminuir la expresión de Bcl-2; por lo tanto, el retraso en la diferenciación y proliferación de las células espermatogénicas y el reducido número de células espermáticas y espermatozoides podrían atribuirse al malatión ${ }^{(25)}$.

En nuestro estudio se demostró que la exposición crónica (14 semanas) de ratas BIOU: Wistar al malatión tiene un impacto en la histofisiología de la gónada masculina. Es por eso por lo que surge una preocupación importante sobre el uso indiscriminado de los pesticidas sin las medidas mínimas generales de protección, lo que puede conllevar a efectos deletéreos en la salud de las personas que manipulan este tipo de sustancias. Nuestro estudio, cuya forma de exposición controlada fue por la vía inhalatoria, similar a la mayoría de las exposiciones crónicas en los seres humanos, es una alerta, aunque no permite extrapolar los resultados a estos. Se recomienda realizar estudios epidemiológicos en humanos expuestos al malatión y correlacionar su potencial efecto como disruptor endocrino sobre el sistema reproductivo masculino.

\section{Fuentes de financiación}

- Las fuentes de financiación de la investigación son provenientes de recursos propios de los autores.

- Se utilizaron ratas machos línea BIOU: Wistar, con un peso promedio de $300 \mathrm{~g}$, suministradas por el bioterio de la universidad de los Andes (ULA), Mérida, Venezuela. Estas permanecieron en las instalaciones del laboratorio de Farmacología y Toxicología de la Facultad de Medicina de la ULA, bajo las condiciones óptimas de preservación de animales de experimentación durante todo el trabajo.

- Se utilizó como material tóxico el malatión, nombre comercial Malathion ${ }^{\circledR} 57$ \%, cuyos componentes son malatión al 57 \% e ingredientes aditivos (43\%). Es fabricado por Insecticidas Internacionales C.A. (INICA). Fue adquirido por financiamiento propio de los autores.

- La determinación de la actividad de la acetilcolinesterasa se llevó a cabo en el laboratorio de farmacología de la facultad de medicina de la ULA. Las muestras fueron procesadas por el método de hidroxamato de Hestrin, modificado por Truhaut y Vernin, y analizadas por espectrofotometría a $520 \mathrm{~nm}$.

- El estudio histopatológico con microscopía de luz se realizó en el departamento de patología de la Universidad de Los Andes, Mérida, Venezuela.

\section{Conflictos de interés}

Los autores declaran no tener ningún conflicto de interés.

\section{Referencias}

1. Diamanti-Kandarakis E, Bourguignon J-P, Giudice LC, Hauser R, Prins GS, Soto AM, et al. Endocrine-disrupting chemicals: an Endocrine Society scientific statement. Endocr Rev. 2009;30(4):293-342.

2. Sifakis S, Androutsopoulos VP, Tsatsakis AM, Spandidos DA. Human exposure to endocrine disrupting chemicals: effects on the male and female reproductive systems. Environ Toxicol Pharmacol. 2017;51:56-70.

3. Safe S. Endocrine disruptors and falling sperm counts: lessons learned or not! Asian J Androl. 2013;15(2):191-4.

4. Slutsky M, Levin JL, Levy BS. Azoospermia and oligospermia among a large cohort of DBCP applicators in 12 countries. Int J Occup Environ Health. 1999;5(2):116-22.

5. Perry MJ, Venners SA, Chen X, Liu X, Tang G, Xing H, et al. Organophosphorous pesticide exposures and sperm quality. Reprod Toxicol Elmsford $\mathrm{N}$. 2011;31(1):75-9.

6. Jouannet P, Wang C, Eustache F, Kold-Jensen T, Auger J. Semen quality and male reproductive health: the controversy about human sperm concentration decline. APMIS Acta Pathol Microbiol Immunol Scand. 2001;109(5):333-44.

7. Jabłońska-Trypuć A, Wołejko E, Wydro U, Butarewicz A. The impact of pesticides on oxidative stress level in human organism and their activity as an endocrine disruptor. J Environ Sci Health B. 2017;52(7):483-94.

8. Suresh NB, Malik JK, Rao GS, Aggarwal M, Ranganathan V. Effects of subchronic malathion exposure on the pharmacokinetic disposition of pefloxacin. Environ Toxicol Pharmacol. septiembre de 2006;22(2):167-71.

9. Rezg R, Mornagui B, El-Fazaa S, Gharbi N. Biochemical evaluation of hepatic damage in subchronic exposure to malathion in rats: effect on superoxide dismutase and catalase activities using native PAGE. C R Biol. 2008;331(9):655-62.

10. Rezg R, Mornagui B, El-Fazaa S, Gharbi N. Caffeic acid attenuates malathion induced metabolic disruption in rat liver, involvement of acetylcholinesterase activity. Toxicology. 2008;250(1):27-31.

11. Contreras HR, Bustos-Obregón E. Morphological alterations in mouse testis by a single dose of malathion. J Exp Zool. 1999;284(3):355-9.

12. Penna-Videau S, Bustos-Obregón E, Cermeño-Vivas JR, Chirino D. Malathion Affects Spermatogenic Proliferation in Mouse. Int J Morphol. 2012;30(4):1399-407.
13. Truhaut R, Vernin H. [micromethod of determination of true cholinesterase activity in whole blood]. Ann Biol Clin (Paris). 1964;22:419-28.

14. Duty SM, Silva MJ, Barr DB, Brock JW, Ryan L, Chen Z, et al. Phthalate exposure and human semen parameters. Epidemiol Camb Mass. 2003;14(3):269-77.

15. Mocarelli P, Gerthoux PM, Patterson DG, Milani S, Limonta G, Bertona M et al. Dioxin Exposure, from Infancy through Puberty, Produces Endocrine Disruption and Affects Human Semen Quality. Environ Health Perspect. 2008;116(1):70-7.

16. Abell A, Ernst E, Bonde JP. Semen quality and sexual hormones in greenhouse workers. Scand J Work Environ Health. 2000;26(6):492-500.

17. Juhler RK, Larsen SB, Meyer O, Jensen ND, Spanò M, Giwercman A, et al. Human semen quality in relation to dietary pesticide exposure and organic diet. Arch Environ Contam Toxicol. 1999;37(3):415-23.

18. Oliva A, Spira A, Multigner L. Contribution of environmental factors to the risk of male infertility. Hum Reprod Oxf Engl. 2001;16(8):1768-76.

19. Larsen SB, Giwercman A, Spanò M, Bonde JP. A longitudinal study of semen quality in pesticide spraying Danish farmers. The ASCLEPIOS Study Group. Reprod Toxicol Elmsford N. 1998;12(6):581-9.

20. Padungtod C, Savitz DA, Overstreet JW, Christiani DC, Ryan LM, Xu X. Occupational pesticide exposure and semen quality among Chinese workers. J Occup Environ Med. 2000;42(10):982-92.

21. Lifeng T, Shoulin W, Junmin J, Xuezhao S, Yannan L, Qianli W, et al. Effects of fenvalerate exposure on semen quality among occupational workers. Contraception. 2006;73(1):92-6.

22. Hernández AF, Parrón T, Tsatsakis AM, Requena M, Alarcón R, LópezGuarnido 0. Toxic effects of pesticide mixtures at a molecular level: their relevance to human health. Toxicology. 2013;307:136-45.

23. Schug TT, Janesick A, Blumberg B, Heindel JJ. Endocrine disrupting chemicals and disease susceptibility. J Steroid Biochem Mol Biol. 2011;127(35):204-15.

24. Sharpe RM. Environmental/lifestyle effects on spermatogenesis. Philos Trans R Soc B Biol Sci. 2010;365(1546):1697-712.

25. Geng X, Shao H, Zhang Z, Ng JC, Peng C. Malathion-induced testicular toxicity is associated with spermatogenic apoptosis and alterations in testicular enzymes and hormone levels in male Wistar rats. Environ Toxicol Pharmacol. 2015;39(2):659-67. 
26. Slimen S, Saloua EF, Najoua G. Oxidative stress and cytotoxic potential of anticholinesterase insecticide, malathion in reproductive toxicology of male adolescent mice after acute exposure. Iran J Basic Med Sci. 2014:17(7):522-30.

27. Uzun FG, Kalender S, Durak D, Demir F, Kalender Y. Malathion-induced testicular toxicity in male rats and the protective effect of vitamins $\mathrm{C}$ and $\mathrm{E}$. Food Chem Toxicol Int J Publ Br Ind Biol Res Assoc. 2009;47(8):1903-8.

28. Krause W. Influence of DDT, DDVP and malathion on FSH, LH and testosterone serum levels and testosterone concentration in testis. Bull Environ Contam Toxicol. 1977;18(2):231-42.

29. Choudhary N, Goyal R, Joshi SC. Effect of malathion on reproductive system of male rats. J Environ Biol. 2008;29(2):259-62.

30. Bustos-Obregón E, González-Hormazabal P. Effect of a single dose of malathion on spermatogenesis in mice. Asian J Androl. 2003;5(2):105-7.

31. Navarro OE, Bustos HR, Molina HK, Arriaza C. Efecto del insecticida malathion sobre el epitelio germinativo de testículo de ratón cf1. Interciencia Rev Cienc Tecnol América. 2015;40(8):560-3.
32. Fernández A. DG, Mancipe G. LC, Fernández A. DC. intoxicación por organofosforados. Rev Med. junio de 2010;18(1):84-92.

33. Uzunhisarcikli M, Kalender Y, Dirican E, Kalender S, Ogutcu A, Buyukkomurcu F. Acute, subacute and subchronic administration of methyl parathion-induced testicular damage in male rats and protective role of vitamins C and E. Pestic Biochem Physiol. 2007;87:115-22.

34. Koji T, Hishikawa Y. Germ cell apoptosis and its molecular trigger in mouse testes. Arch Histol Cytol. 2003;66(1):1-16

35. Youle RJ, Strasser A. The BCL-2 protein family: opposing activities that mediate cell death. Nat Rev Mol Cell Biol. 2008;9(1):47-59.

36. Korsmeyer SJ. BCL-2 gene family and the regulation of programmed cell death. Cancer Res. 1999;59(7 Suppl):1693s-700s.

37. Basu A, Haldar S. The relationship between BcI2, Bax and p53: con sequences for cell cycle progression and cell death. Mol Hum Reprod. 1998;4(12):1099-109. 